\title{
Simple Screening Tests for Peripheral Neuropathy as a Prediction of Diabetic Foot Ulceration
}

\author{
by Ghada M. Morshed MRCS, MD¹, Mohamed A. Mashahit, MD², Hala A. Shaheen, MD³
}

The Foot and Ankle Online Journal 4 (11): 2

Background and Objectives: Diabetes mellitus is one of the major health problems, and one of its commonest complications is peripheral neuropathy. The aim of this study is to evaluate four standard simple screening tests (10-g Semmes-Weinstein monofilament examination $\{S W M E\}$, vibration sensation by a $128 \mathrm{~Hz}$ tuning fork, superficial pain test and ankle reflex) for detection of neuropathy using the nerve conduction study (NCSs) as the standard criterion in diabetic patients.

Methods: The study included 120 patients with diabetes mellitus, all patients had complete clinical assessment including presence or absence of neuropathy, exclusion of other causes of neuropathy, NCS, $10 \mathrm{~g}$ Semmes-Weinstein monofilament examination, vibration sensation by a $128 \mathrm{~Hz}$ tuning fork, superficial pain sensation and ankle reflex were done for all patients.

Results: Foot care practices were followed by 80 (66.6\%) of the study population. When compared with NCSs, the monofilament was the most specific at $91 \%$, less sensitive $57 \%$, superficial pain, ankle reflex had lower specificity (36\%, 41\%) respectively, sensitivity (62\%,57\%) respectively. Tuning fork had specificity $90 \%$, sensitivity $56 \%$.

Conclusion: The study findings show that the simple screening tests (10-g SWME, vibration testing, superficial pain test and ankle reflex) can be used confidently for annual screening of diabetic neuropathy in diabetic patients.

Key Words: Monofilament-tuning fork-ankle reflex-superficial pain-neuropathy.

Accepted: October, 2011

Published: November, 2011

This is an Open Access article distributed under the terms of the Creative Commons Attribution License. It permits unrestricted use, distribution, and reproduction in any medium, provided the original work is properly cited. (The Foot and Ankle Online Journal (www.faoj.org), 2011 All rights reserved.

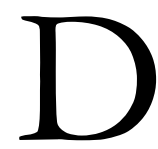
iabetes mellitus is considered as a major health problem and one of its commonest complications involves the feet. Diabetic foot problems may lead to lower limb amputation which occurs commonly in uncontrolled diabetics. The chronic peripheral neuropathy which is associated with diabetes presents progressively and insidiously with poor symptoms related to the pathological severity. ${ }^{1,2}$

Address correspondence to: Ghada Morshed Ahmed Morshed, Galal El Deen El Seuty, El Manial, Cairo, Egypt. E-mail: ghadamorshed@yahoo.com. Tel: 0125870476

${ }^{1,2,3}$ Departments of Surgery ${ }^{1}$, Internal Medicine ${ }^{2}$ and Neurology ${ }^{3}$. Faculty of Medicine, Fayoum University, Cairo, Egypt.
Peripheral neuropathy initiates the pathophysiology to leg ulceration and may be amputation and it is the main cause for sensory ataxia, painful paresthesia, and Charcot deformity. ${ }^{3}$ Early identification and screening of neuropathy offer an important opportunity for the diabetic patient to actively alter the suboptimal glycemic control and improve foot care prior to significant morbidity. ${ }^{4}$ Electrophysiological studies have shown the relation between glycated hemoglobin and the presence and also the severity of neuropathy. ${ }^{5}$ 


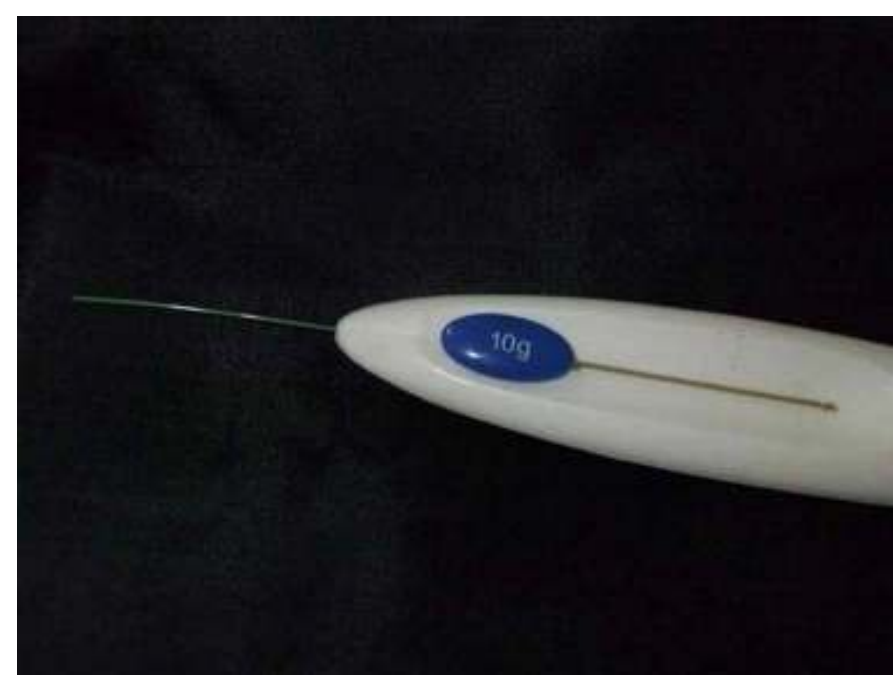

Figure 110 gram sensory monofilament.

The aim of this study is to evaluate four standard simple screening tests (10-g Semmes-Weinstein monofilament examination $\{\mathrm{SWME}\}$, vibration sensation by a128 Hz tuning fork, ankle reflex and superficial pain test) for detection of neuropathy using the NCSs as the standard criterion in diabetic patients.

\section{Patient and Methods}

Our study included 120 diabetic patients between March 2010 to July 2011, history taking of duration of diabetes, associated diseases, presence or absence of neuropathy (e.g. foot pain, tingling, numbness, imbalance, weakness and upper limb symptoms) and its duration if present, and they were examined as follows:

1. Exclusion of other causes of neuropathy (e.g. familial, nutritional, uremic, and alcoholic) by comprehensive examination medically and neurologically.

2. Standardized NCSs (bilateral) including motor (tibial, peroneal, median, and ulnar) and sensory (sural, median, and ulnar) nerves - performed by a blinded technicians to the status of the patient.

3. A10-g SWME (Fig. 1) superficial pain and vibration sense by a $128 \mathrm{~Hz}$ tuning fork (Fig. 2a,b) and ankle reflex, all were performed by a third examiner who is blinded to the history, physical examination and the results of NCSs.

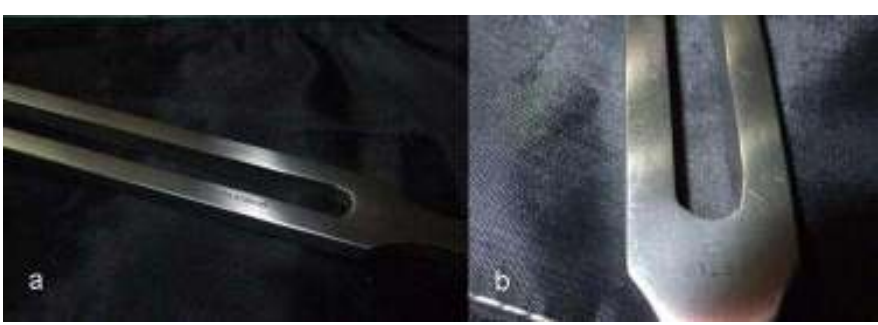

Figure $\mathbf{2 a}$ and $\mathbf{2 b} 128 \mathrm{hz}$ tuning fork.

All data were entered on standardized forms, subjects identification was by number, date of birth, and initials.

\section{Sensory testing methods}

The patient was given a reference sensation by application of the stimulus to the sternum and then asked the nature of the sensation perceived. When the nature of the sensation was perceived accurately on the sternum, the patient was asked, with eyes closed, to describe the sensations experienced sequentially at the sites described below:

The SWME was conducted using a $10-\mathrm{g}$ monofilament applied to a no callused site on the dorsum of the first toe just proximal to the nail bed. It was repeated four times on both feet in an arrhythmic manner. The SWME threshold was defined as the total number of times the application of $10-\mathrm{g}$ monofilament was not perceived by the patient, and it varied from 0 to 8.

Vibration testing by a $128-\mathrm{Hz}$ tuning fork applied to the bony prominence bilaterally situated at the dorsum of the first toe just proximal to the nail bed. The patient was asked to report the time at which vibration diminished beyond perception. The tuning fork was then applied to the dorsal aspect of the distal phalanx of the examiner's thumb. The time (in seconds) at which vibration sensation diminished beyond the examiner's perception was then recorded on a standardized form. The values from both sides were added to provide a single score for statistical analyses. 


\begin{tabular}{|c|c|c|c|c|c|}
\hline Test & Sensitivity \% & Specificity\% & PPV\% & NPV\% & P-value \\
\hline Monofilament & 57 & 91 & 94 & 44 & $P<0.001$ \\
\hline Superficial Pain & 62 & 36 & 49 & 50 & $P=0.99$ \\
\hline Tuning fork & 56 & 90 & 93 & 44 & $P<0.001$ \\
\hline Ankle reflex & 57 & 41 & 53 & 44 & $P<0.10$ \\
\hline
\end{tabular}

Table 1 Sensitivity, specificity and P-value of the four tests. PPV (positive predictive value), NPV (negative predictive value).

The vibration test threshold was defined as the total number of times the application of the vibrating tuning fork and the dampening of vibration was not felt, with scores varying between 0 and 8 .

Superficial pain sensation was conducted using a sterile Neurotip ${ }^{\text {TM }}$ (Owen Mumford) applied four times to the two sites described in SWME. The superficial pain threshold was defined as the total number of times the application of the pain sensation was not perceived, with scores varying from 0 to 8 . Ankle reflex was assessed with a tendon hammer and was recorded as either present or absent.

\section{Criterion standard}

Standardized techniques for NCSs were applied with temperature control and fixed distances. Measurements of latencies, distances, and amplitudes were assessed in a standard fashion using onset latencies and baseline to peak amplitudes. Initial positive peak (if present) to negative peak measurements were conducted for sensory responses. $\mathrm{F}$ waves were generated for all motor nerves, and minimal, reproducible latencies were measured. Conduction velocities were calculated for motor and sensory nerves.

All conduction velocity and distal amplitude values for the NCSs were given a score of 0 for normal and 1 for abnormal. The mean reference values+-2SD were taken as the normal range. The maximum NCS score if all parameters were abnormal was 28 points (16 motor and 12 sensory).The total NCS score was defined as the sum of the number of abnormal values.

\section{Statistical analyses}

The data were analyzed and we used the X2 test to detect the difference of results across the four tests compared to NCSs, $\mathrm{P}<0.01$ was considered statistically significant. By constructing Receiver operating characteristic curve, sensitivity, specificity, positive and negative predictive values were calculated for the various tests using NCS as the gold standard definition of neuropathy.

\section{Results}

The study included 120 diabetic patients .The mean age was 52.2 44.8 (range 22-85years), 59 males (49.2\%), 61 females (50.8\%). In the study all patients had type2diabetes, the mean duration of diabetes was $8.21 \pm 7.81$ years and mean FPG 202.15 $\pm 50.44 \mathrm{mg} / \mathrm{dl}$, $80.2 \%$ were receiving oral hypoglycemic drugs, $19.8 \%$ were receiving insulin .Foot care practices were followed by $80(66.6 \%)$ patients of the study population by optimization of the glycemic control, cessation of smoking, prescription of adequate proper fit foot wear with wide deep box and debridement of calluses with follow up at 6 months and 12 months.

Evaluation of neuropathy by nerve conduction study (NCSs) showed peripheral neuropathy in 75 patients $(62.5 \%)$, using other testing modalities neuropathy was found in $56(46.6 \%)$ patients with monofilament, in $45(37.5 \%)$ with Superficial pain test, in $57(47.5 \%)$ with vibration test and in $56(46.6 \%)$ with ankle reflex. 
Table 1 presents the sensitivity, specificity, PPV, NPV and $\mathrm{P}$-value of each diagnostic test compared with NCSs which was taken as the gold standard.

\section{Discussion}

In this study we used NCS as a standard criterion for the diagnosis of peripheral neuropathy. Since peripheral neuropathy is a main element in causing of both foot ulceration and amputation so selection of rapid, simple and accurate testing method for diagnosis of peripheral neuropathy in diabetic patients is so important and apart from NCS we select monofilament, superficial pain, tuning fork and ankle reflex for evaluation of peripheral neuropathy.

The most frequently used modality for peripheral neuropathy detection is the nylon Semmes-Weinstein monofilament. ${ }^{7}$ Inability to perceive $10 \mathrm{~g}$ of force 5.07 monofilament applies is associated with clinically significant large-fiber neuropathy. In our study monofilament showed a sensitivity $57 \%$ and a specificity $91 \%$ compared to other studies with $95 \%$ sensitivity and $82 \%$ specificity, ${ }^{8,9}$ other studies showed sensitivity of $77 \%$ and specificity $96 \%$, also another study showed senility $66 \%$ and $34 \%$ specificity. $^{10}$

The $128 \mathrm{~Hz}$ tuning fork in our study showed sensitivity of $56 \%$ and specificity of $90 \%$ compared to other study sensitivity and specificity was 53\% and 99\% respectively. The superficial pain test in our study showed sensitivity and specificity of $62 \%$ and $36 \%$ respectively $59 \%$ and $97 \%$ respectively. ${ }^{6}$ The ankle reflex in our study showed sensitivity and specificity of $57 \%$ and $41 \%$ respectively compared to other studies showed sensitivity and specificity of $75 \%$ and $89 \%$ respectively. ${ }^{11}$

\section{Conclusion}

In our study we found that the simple screening tests (10g SWME, vibrating test, superficial pain test and ankle reflex) can be used confidently for annual screening of diabetic neuropathy in diabetic patients.

\section{References}

1. Britland ST, Young RJ, Sharma AK, Clarke BF. Association of painful and painless diabetic polyneuropathy with different patterns of nerve fiber degeneration and regeneration. Diabetes 1990 39: 898-908.

2. Ochoa J. Positive sensory symptoms in neuropathy: mechanisms and aspects of treatment. In Peripheral Nerve Disorders, 2nd ed. Asbury A, Thomas P (Eds) Oxford, UK, Butterworth-Heinemann, 1995, pp 44-58.

3. Pecoraro RE, Reiber GE, Burgess EM. Pathways to diabetic limb amputation: basis for prevention. Diabetes Care 1990 13: 513-521.

4. Diabetes Control and Complications Trial Research Group. The effect of intensive treatment of diabetes on the development and progression of longterm complications in insulin-dependent diabetes mellitus. N Eng J Med 1993 329: 977-986.

5. Tkac I, Bril V. Glycemic control is related to the electrophysiologic severity of diabetic peripheral sensorimotor polyneuropathy. Diabetes Care 1998 21: 1749-1752.

6. Perkins BA, Olaleye D, Zinman B, Bril V. Simple screening tests for peripheral neuropathy in the diabetes clinic. Diabetes Care 2001 24: 250-256.

7. Armstrong DG. The 10-g monofilament: the diagnostic divining rod for the diabetic foot? Diabetes Care 2000 23: 984-988.

8. Armstrong DG, Lavery LA, Vela SA, Quebedeaux TL, Fleischli JG. Choosing a practical screening instrument to identify patients at risk for diabetic foot ulceration. Arch Intern Med 1998 158: 289-292.

9. de Sonnaville JJ, Colly JLP, Wijkel D, Heine RJ. The prevalence and determinants of foot ulceration in type II diabetic patients in a primary health care setting. Diabetes Res Clin Pract 1997 35: 149-156.

10. Boyko EJ, Ahroni JH, Stensel V, Forsberg RC, Davignon DR, Smith DG. A prospective study of risk factors for diabetic foot ulcer. The Seattle Diabetic Foot Study. Diabetes Care 1999 22: 10361042.

11. Tre GS, Lisbô HR, Syllo R, Canan LH, Gros JL. Prevalence and characteristics of diabetic polyneuropathy in Passo Fundo, South of Brazil. Arq Bras Endocrinol Metabol 2007 51: 987-992. 